Supporting Information:

\title{
Quantitative Evaluation of Long-Range and Cooperative Ion Effect on Water in Polyamide Network
}

\author{
Ki Chul Park and Takehiko Tsukahara* \\ Laboratory for Advanced Nuclear Energy, Institute of Innovative Research in Tokyo Institute of \\ Technology, 2-12-1-N1-6 O-okayama, Meguro-ku, Tokyo 152-8550, Japan \\ *E-mail: ptsuka@lane.iir.titech.ac.jp
}

\section{Table of Contents}

1. Determination of photonic crystal structures from the diffraction wavelength of transmission

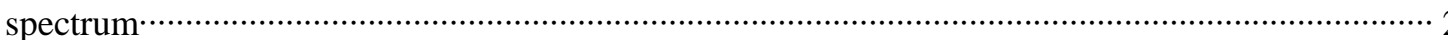

Figure S1. Transmission spectrum of $\mathrm{SiO}_{2}$-NCP-CCA/DMF liquid membranes.

2. Thermal response of photonic crystal PNPAAm hydrogel membrane sensor …………………….... 3

Figure S2. Color change of photonic crystal PNIPAAm hydrogel membranes with the increase of temperatures in ultrapure water.

3. Specific ion adsorption on the surface of silica nanoparticles …................................................. 4

Figure S3. Enlarged views of the $\Pi-\Delta V_{\text {fcc }}$ plot (Figure 2A) of alkali chloride (a) and nitrate (b) solutions in the low salt concentration region and the $\mathrm{pH}$ values of the salt solutions (c).

4. Calculation of osmotic coefficients and osmotic pressures of salt solutions ………......................... 5

5. Calculation of the volume change of photonic crystal unit cell …................................................. 11

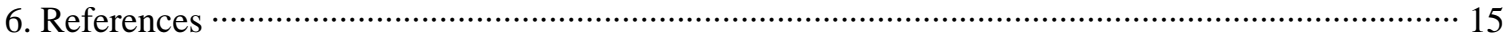


1. Determination of photonic crystal structures from the diffraction wavelength of transmission $\underline{\text { spectrum }}^{[1]}$

The sample for measurements was prepared by sandwiching $\mathrm{SiO}_{2}-\mathrm{NCP}-\mathrm{CCA} / N, N$ dimethylformamide (DMF) dispersions between the quartz plate with a rectangular template (which was made of polyimide film tape, the size of mold space: $7 \times 20 \mathrm{~mm}^{2}$, depth: $63 \mu \mathrm{m}$ ) and another quartz plate. The transmission spectrum of the resulting liquid membrane was measured at the incident-light glancing angle $\theta_{0}$ and detection angle of $90^{\circ}$ to the plane of the sample. The diffracted-light wavelength was observed at $390.7 \mathrm{~nm}$ (Figure S1).

The diffracted-light wavelength $\left(\lambda_{0}\right)$ of specific crystal structures can be calculated by using the equations (E1) and (E2) derived from Bragg's and Snell's laws (for detailed explanation, see Section 5 ), which is dependent on the average refractive index $\left(n_{\text {avg }}\right)$ of the $\mathrm{SiO}_{2}-\mathrm{NCP}-\mathrm{CCA} / \mathrm{DMF}$, the crystal lattice spacing $\left(d_{h k l}\right)$ and glancing angle $(\theta)$ in silica CCA/DMF.

$$
\begin{aligned}
& \lambda_{0}=2 n_{a v g} d_{h k l} \sin \theta \\
& \theta=\cos ^{-1}\left[\frac{\cos \theta_{0}}{n_{a v g}}\right]
\end{aligned}
$$

The volume percentage of silica CCA was $17.1 \%$, and the mean particle diameter determined by dynamic light scattering (Delsa Nano HC, Beckman Coulter, Inc.) was $102 \mathrm{~nm}$. The $n_{\text {avg }}$ calculated from the volume fractions of DMF and silica nanoparticles and the refractive indices of DMF $\left(n_{\mathrm{DMF}}=1.43^{[2]}\right)$ and silica $\left(n_{\mathrm{Si}_{2}}=1.47^{[3,4])}\right.$ was 1.44 . The $d_{111}$ spacing of face-centered cubic (fcc) crystal lattice and the $d_{110}$ spacing of body-centered cubic (bcc) crystal lattice were $135.6 \mathrm{~nm}$ and $131.9 \mathrm{~nm}$, respectively. The diffraction wavelength calculated using the above-mentioned parameters was $389.3 \mathrm{~nm}$ for the fcc(111) diffraction, and $378.4 \mathrm{~nm}$ for the bcc(110) diffraction. The good agreement of the calculated wavelength for the fcc(111) diffraction with that observed in the transmission spectrum indicates that the crystal structure of silica CCA is fcc. 


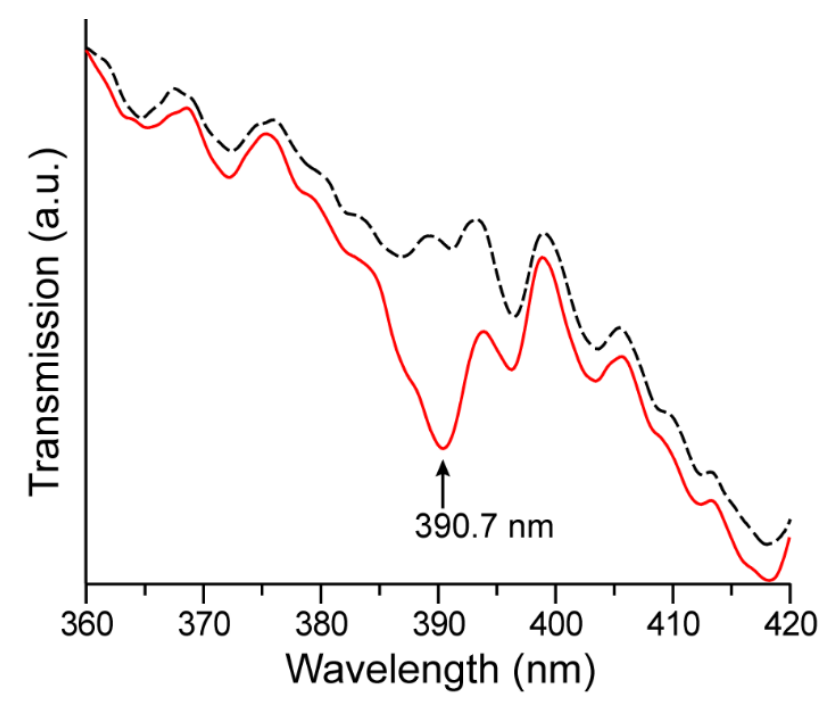

Figure S1. Transmission spectrum of $\mathrm{SiO}_{2}-\mathrm{NCP}-\mathrm{CCA} / \mathrm{DMF}$ liquid membranes. The dashed line spectrum is a background spectrum without photonic crystals. The wavelength and intensity of the peak observed at $390.7 \mathrm{~nm}$ were varied by tilting the quartz cell filled with silica CCA/DMF dispersion to the incident light. Therefore, the 390.7-nm peak was assigned to the wavelength of diffracted light by silica CCA crystals.

\section{Thermal response of photonic crystal PNPAAm hydrogel membrane sensor}

The color changes with the thermal-induced dehydration of the PNIPAAm hydrogel membrane (Figure S2) become evaluation criteria in the batch experiments of ion sensing. As the hydrogel dehydration proceeds, the color changes as follows: the metallic greenish blue $\rightarrow$ stronger blue $\rightarrow$ purplish blue $\rightarrow$ gradual disappearance of color (below LCST) $\rightarrow$ finally colorless (at the LCST of 32 $\left.{ }^{\circ} \mathrm{C}\right)$.

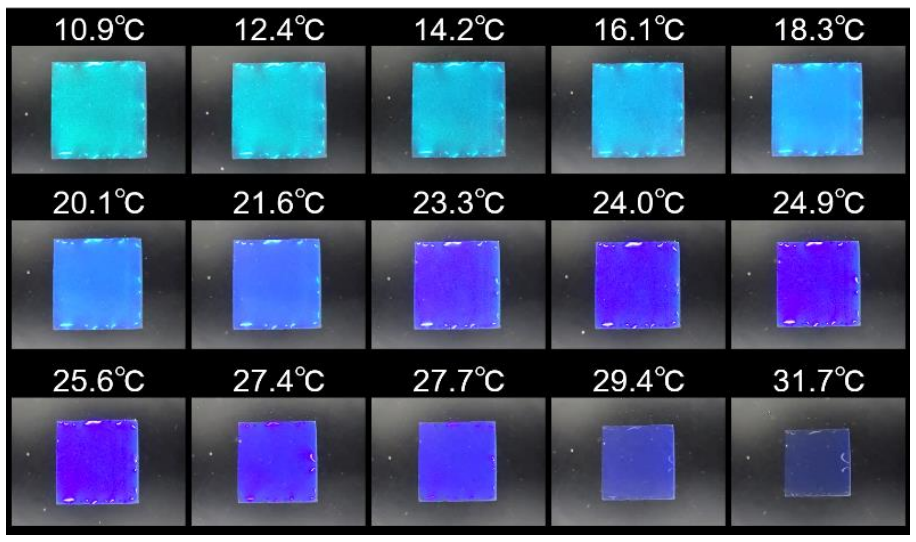

Figure S2. Color change of photonic crystal PNIPAAm hydrogel membranes with the increase of temperatures in ultrapure water. The size of initial membrane: $7 \times 7 \mathrm{~mm}^{2}$, thickness: $>63 \mu \mathrm{m}$. 


\section{Specific ion adsorption on the surface of silica nanoparticles}

Adsorption of alkali cations on silica surface has been found to follow a direct Hofmeister series, i.e., $\mathrm{Cs}^{+}>\mathrm{K}^{+}>\mathrm{Na}^{+}>\mathrm{Li}^{+}$, which is inversely related to the hydration energy of the cations ${ }^{[5]}$. However, some theoretical or experimental studies claimed that smaller alkali cations more strongly bind to silica surface (i.e., $\left.\mathrm{Li}^{+}>\mathrm{Cs}^{+}\right)^{[6,7]}$, where more deprotonated silanol groups were suggested to favor $\mathrm{Li}^{+}$binding at a higher $\mathrm{pH}$ exceeding the limit value of around $\mathrm{pH}=6^{[7]}$. Furthermore, a recent spectroscopic study demonstrated a pH-dependent inversion of the direct Hofmeister series of alkali cation adsorption at neutral $\mathrm{pH}$ region to the reverse Hofmeister series $(\mathrm{CsCl}<\mathrm{KCl}<\mathrm{NaCl}<\mathrm{LiCl})$ at $\mathrm{pH}<6$ and at $\mathrm{pH}>$ $10^{[8]}$. The reversal of the direct Hofmeister series at the high $\mathrm{pH}$ was attributed to the exclusion of $\mathrm{Cs}^{+}$ from silica surface and the more favored adsorption of smaller $\mathrm{Li}^{+}$and $\mathrm{Na}^{+}$, which would be caused respectively by the displacement of $\mathrm{Cs}^{+}$with water molecules more strongly hydrogen-bonded to the silica surface and by that of the hydrogen-bonded water molecules with strongly hydrated and kosmotropic cations. Furthermore, the more preferential adsorption of $\mathrm{Li}^{+}$than $\mathrm{Cs}^{+}$at low $\mathrm{pH}$ was attributed to contribution from the asymmetric hydration of cations with water molecules and surface silanols at an outer Helmholtz plane ${ }^{[8]}$. In the spectroscopic study, the measurement was conducted at the time scale with almost no influence by silica dissolution. Therefore, the role of silica dissolution on water structure was not considered, and the cation adsorption was attributed to surface hydration forces rather than electrostatics. At high $\mathrm{pH}$, however, the exclusion of $\mathrm{Cs}^{+}$and specific adsorption of $\mathrm{Li}^{+}$ would be more remarkable for the increasingly deprotonated silica, to which water molecules are more strongly hydrogen-bonded. The dissociation constant $(\mathrm{pKa})$ of $\mathrm{Si}-\mathrm{OH}$ for deprotonation is reported over the wide range in the $\mathrm{pH}$ region (e.g., $\mathrm{p} K \mathrm{a}=7.5^{[9]}, \mathrm{p} K \mathrm{a}=4.0^{[10]}$, two types of silanols ${ }^{[11]}$, i.e., $\mathrm{p} K \mathrm{a}=4.5$ (population; 19\%) and 8.5 (population; $81 \%$ ), or the bimodal acidity values differing by the local environment of $\left.\mathrm{Si}-\mathrm{OH}^{[12]}\right)$, although it is obvious that the deprotonated amount increases with the increase of $\mathrm{pH}$, and vice versa. The variation profiles of swelling for the alkali cations were different between the chloride and nitrate solutions (Figure S3a,b). The $\mathrm{pH}$ values in the low concentration range $\left(0.030-0.75 \mathrm{~mol} \mathrm{~L}^{-1}\right)$ were decreased with the increase of salt concentrations, although the extent of $\mathrm{pH}$ decrease was dependent on the kind of salts (Figure S3c). The weakly basic $\mathrm{pH}$ (ca. 8.0) of the initial $\mathrm{LiNO}_{3}$ concentration $\left(0.030 \mathrm{~mol} \mathrm{~L}{ }^{-1}\right)$ would significantly enhance the specific adsorption of $\mathrm{Li}^{+}$, facilitating the osmotic swelling, compared with the initial chloride solution of $\mathrm{pH}=\mathrm{ca}$. 6.5. This result is consistent with the previously reported view that more deprotonated silanol groups contribute to the specific binding of $\mathrm{Li}^{+}$to silica surface. On the other hand, the $\mathrm{pH}$ of $\mathrm{CsCl}, \mathrm{NaCl}$ and $\mathrm{KCl}$ solutions in the low concentration range was around neutral. As mentioned above, at the neutral $\mathrm{pH}, \mathrm{Cs}^{+}$adsorption is more favored than the smaller cations, i.e., $\mathrm{Li}^{+}, \mathrm{Na}^{+}$and $\mathrm{K}^{+}$. Therefore, it is considered that the sensor 
membrane was more swollen in $\mathrm{CsCl}$ solutions than in $\mathrm{NaCl}$ and $\mathrm{KCl}$ solutions (Figure $\mathrm{S} 3 \mathrm{a}$ ), due to the Donnan effect caused by the more favored adsorption of $\mathrm{Cs}^{+}$on the charged silica surface.

a

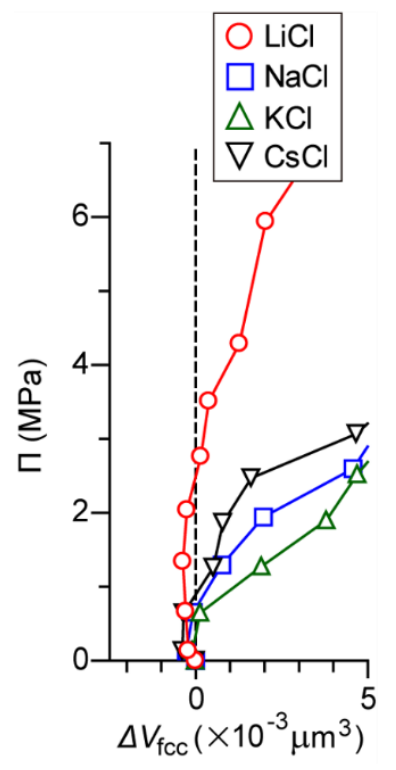

b



C

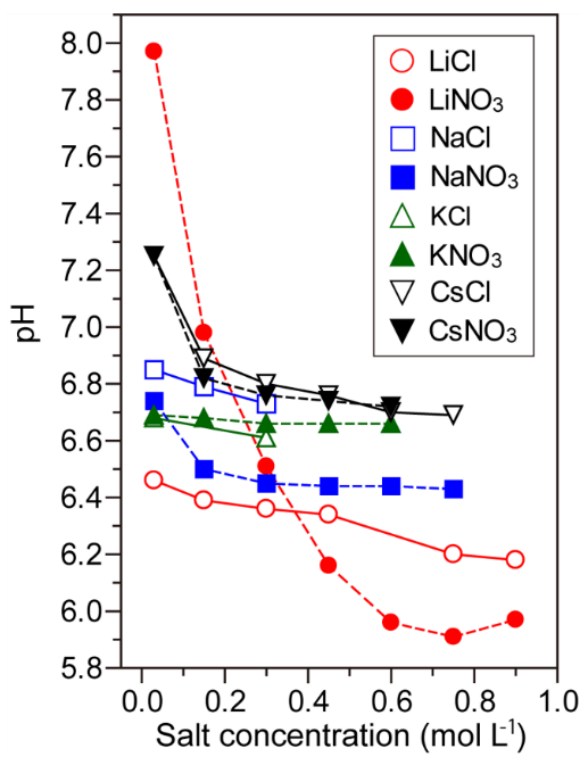

Figure S3. Enlarged views of the $\Pi-\Delta V_{\text {tcc }}$ plot (Figure 2A) of alkali chloride (a) and nitrate (b) solutions in the low salt concentration region and the $\mathrm{pH}$ values of the salt solutions (c). The negative $\Delta V_{\text {fcc }}$ represent the swelling of photonic crystal PNIPAAm hydrogel membrane sensors.

\section{$\underline{\text { 4. Calculation of osmotic coefficients and osmotic pressures of salt solutions }}$}

The osmotic pressure of real solutions, $\Pi(\mathrm{kPa})$, can be calculated by correcting the deviation from the van't Hoff's Law $\left(\Pi_{0}=i C R T\right)$ with the osmotic coefficient $(\phi)$ of electrolyte solution according to the equation (E3):

$$
\Pi=\phi \Pi_{0}=\phi i C \mathrm{RT}
$$

where $i$ is the number of ions produced by dissociation of the solute, $C$ is the concentration of solution $\left(\mathrm{mol} \mathrm{L}^{-1}\right), \mathrm{R}$ is universal gas constant $\left(8.31446 \mathrm{~N} \cdot \mathrm{m} \mathrm{mol}^{-1} \mathrm{~K}^{-1}\right)$, and $\mathrm{T}$ is absolute temperature $(\mathrm{K})$.

The osmotic coefficient is derived from the mean activity coefficient $\left(\gamma_{ \pm}\right)$of the solute through the Gibbs-Duhem relation between the solvent and solute activities. Thus far, various models for accurately 
predicting the thermodynamic properties of electrolyte solutions have been proposed to afford the calculation methods of the mean activity coefficient at $25^{\circ} \mathrm{C}$. Among them, the one-parameter or twoparameter models of Bromley ${ }^{[13]}$, Meissner ${ }^{[14-17]}$ and Pitzer ${ }^{[18-20]}$ have directly extended the DebyeHückel (D-H) model based on long-range interaction (the electrostatic ion-ion interaction) for dilute solutions to enable the application to higher concentration range (maximum molality is $m=6 \mathrm{~mol} \mathrm{~kg}^{-1}$ ). These models are most appropriate to strong, single electrolyte solutions. The Chen's method combined the Pitzer model for long-range interaction with nonrandom two-liquid model for short-range interactions (such as ion-molecule and molecule-molecule interactions). The short-range interactions increase the importance for the solutions of weak electrolytes (which produce significant concentrations of molecular solutes) and the higher concentration of electrolyte solutions. The other models, for example, based on mean spherical approximation account for the excluded volume of ions as well as the short-range and long-range interactions to further extend the applicable concentration range, accurately predicting the activity coefficient of individual ions as well as mean activity coefficients.

In the present study, the osmotic experiments were conducted at $10{ }^{\circ} \mathrm{C}$. In terms of the strong temperature dependence of activity coefficient, it is required to take into account the temperature effect for each electrolyte solution. In one-parameter and two-parameter models, the introduction of temperature effect to the characteristic parameters has been described to adapt the models to any temperature of solutions. In the Bromley model, the osmotic coefficient at any temperature is directly computed from ionic strengths by using the D-H constant for activity coefficients and the characteristic Bromley parameters $(B)$ considering the temperature effect. As suggested by Bromley, the $B$ values for temperature effect can be calculated by utilizing the Meissner's method for reflecting the temperature effect to the activity coefficient. The Meissner's method derives the reduced activity coefficient at a given temperature for any ionic strength from the value at $25^{\circ} \mathrm{C}$, converting it to the mean activity coefficient applicable to the Bromley model.

In the Pitzer model, the osmotic coefficient and the mean activity coefficient have been derived from the excess Gibbs energy using the D-H function and the binary and triple ion interaction terms. Furthermore, the temperature-dependent equations for the parameters of the ion interaction terms have been determined by the extensive investigation on $\mathrm{NaCl}$. In addition, the Pitzer model has provided the temperature-dependent equation of dielectric constant $(D)$ for the calculation of the D-H constant $\left(A_{\phi}\right)$, which is more largely dependent on temperature. The alkali and alkaline earth salts applied to the osmotic experiments in the present study are strong electrolytes, and the concentration range is far below $m=6$ (at most $3.2 \mathrm{~mol} \mathrm{~kg}^{-1}$ for $\mathrm{LiCl}$ ). Therefore, the one-parameter or two-parameter models based on long-range interactions are fully applicable to the accurate calculation of thermodynamic properties of the single salt solutions considered. In the present study, the Bromley and Pitzer models readily available 
for temperature effect were adopted for the computation of osmotic coefficient at $10{ }^{\circ} \mathrm{C}$, which is as described below.

The reduced activity coefficient $\left(\Gamma_{\mathrm{t}}^{\circ}\right)$ for temperature, $t\left({ }^{\circ} \mathrm{C}\right)$, at a given ionic strength $(I)$ can be calculated according to the Meissner's equation $(\mathbf{E 4})^{[14,21]}$ :

$$
\log \Gamma_{\mathrm{t}}^{\circ}=(1.125-0.005 t) \log \Gamma_{25^{\circ} \mathrm{C}}^{\circ}-(0.125-0.005 t) \log \Gamma_{\text {ref }}^{\circ}
$$

where $\Gamma^{\circ}{ }_{25}^{\circ} \mathrm{C}$ is the reduced activity coefficient at $25{ }^{\circ} \mathrm{C}$, and $\Gamma_{\text {ref }}^{\circ}$ is the reference reduced activity coefficient defined as the following equation (E5).

$$
\log \Gamma_{\text {ref }}^{\circ}=\frac{-0.41 \sqrt{I}}{1+\sqrt{I}}+0.039 I^{0.92}
$$

The reduced activity coefficient is defined as the equation (E6) represented by the mean molal activity coefficient, $\gamma_{ \pm}$, and the charge number of ions, $z_{+}$and $z_{-}^{[15-17]}$.

$$
\Gamma^{\circ} \equiv \gamma_{ \pm}^{\frac{1}{z_{+} z_{-}}}
$$

The reduced activity coefficient at $25{ }^{\circ} \mathrm{C}$ is calculated by combining the equation (E6) with the following Bromley equation (E7) for mean activity coefficient of single electrolyte solutions ${ }^{[13] \text { : }}$

$$
\log \gamma_{ \pm}=\frac{-A_{\gamma}\left|z_{+} z_{-}\right| \sqrt{I}}{1+\rho \sqrt{I}}+\frac{(0.06+0.6 B)\left|z_{+} z_{-}\right| I}{\left(1+\frac{1.5}{\left|z_{+} z_{-}\right|} I\right)^{2}}+B I
$$

where $\rho$ is a constant of D-H equation, which is related to the distance of closest approach of ions in solution, and $A_{\gamma}$ corresponds to the D-H constant for activity coefficients. The $\rho$ value at $25{ }^{\circ} \mathrm{C}$ for the salts with the valence type of $z_{+}-z_{-}=1-1,2-1,1-2,2-2,3-2$, and $1-4$ can be set to 1.0 , which is regarded as being independent of temperature. The values of $B$ for the specific electrolytes at $25^{\circ} \mathrm{C}$ are listed in the Bromley's report ${ }^{[13]}$. The $A_{\gamma}$ is calculated according to the following equation $(\mathbf{E 8})^{[22]}$ : 


$$
A_{\gamma}=\frac{1}{2.303}\left(\frac{e}{\sqrt{D \mathrm{kT}}}\right)^{3} \sqrt{\frac{2 \pi \mathrm{d}_{0} \mathrm{~N}_{\mathrm{A}}}{1000}}
$$

where $\mathrm{d}_{0}$ represents the solvent density at the given temperature, $\mathrm{T}(\mathrm{K}), D$ is the dielectric constant at $\mathrm{T}$, $\mathrm{k}$ is Boltzmann's constant $\left(1.38045 \times 10^{-16} \mathrm{erg} \mathrm{K}^{-1}\right), \mathrm{N}_{\mathrm{A}}$ is Avogadoro's number $\left(6.0232 \times 10^{23}\right)$, and $e$ represents electronic charge $\left(4.8029 \times 10^{-10}\right.$ e.s.u. $)$. The reduced activity coefficient at $t$ calculated from the values of $\Gamma^{\circ}{ }_{25}^{\circ} \mathrm{C}$ and $\Gamma^{\circ}$ ref is converted to the mean activity coefficient at the temperature by using the equation (E6). The $B$ value considering temperature effect is derived from the mean activity coefficient at the given temperature and ionic strength by using the Bromley equation (E7).

The $\phi$ value is calculated by using the equation of $(\mathbf{E 9})$ with the terms of $(\mathbf{E 1 0})$ and $(\mathbf{E 1 1})^{[13]}$ :

$$
\begin{gathered}
\phi=1-2.303 A_{\gamma}\left|z_{+} z_{-}\right| \frac{\sqrt{I}}{3} \sigma\left(\rho I^{1 / 2}\right)+2.303(0.06+0.6 B)\left|z_{+} Z_{-}\right| \frac{1}{2} \psi(a I)+2.303 B \frac{I}{2} \\
\sigma\left(\rho I^{1 / 2}\right)=\frac{3}{\left(\rho I^{1 / 2}\right)^{3}}\left[1+\rho I^{1 / 2}-\frac{1}{1+\rho I^{1 / 2}}-2 \ln \left(1+\rho I^{1 / 2}\right)\right] \quad \text { (E10) } \\
\psi(a I)=\frac{2}{a I}\left[\frac{1+2 a I}{(1+a I)^{2}}-\frac{\ln (1+a I)}{a I}\right]-2.303 B \frac{I}{2}
\end{gathered}
$$

Here, $a=1.5 / z_{+} z-\mid$ and, as above mentioned, $\rho=1.0$ are used. The $\phi$ value at the given temperature and ionic strength is calculated using the $B$ parameter for that temperature and ionic strength. The osmotic coefficient at $10{ }^{\circ} \mathrm{C}$ for each ionic strength was calculated according to the above Bromley and Meissner methods, and applied to the computation of osmotic pressure for all of the alkali and alkaline earth salt solutions considered in the present study. The ionic strength was calculated from the molal concentration of salt solutions. The concentration unit conversion from molarity to molality was carried out by the interpolation of the fourth-order polynomial least-squares fit curve for the plot of molality vs molarity based on the literature data for each electrolyte solution ${ }^{[23-28]}$. All the curve fitting results for the salt solutions considered in this study provided the determination coefficient $\mathrm{R}^{2}=1$. 
For comparison, the osmotic coefficients were also calculated using the Pitzer model for single, strong electrolyte solutions. The osmotic coefficients can be directly calculated using the equation (E12) with the terms represented by $(\mathbf{E 1 3})$ and $(\mathbf{E 1 4})^{[19]}$ :

$$
\begin{gathered}
\phi=1+\left|z_{+} z_{-}\right| f^{\phi}+m \frac{2 v_{+} v_{-}}{v} B^{\phi}+m^{2} \frac{2\left(v_{+} v_{-}\right)^{3 / 2}}{v} C^{\phi} \\
f^{\phi}=-A_{\phi} \frac{I^{1 / 2}}{1+b I^{1 / 2}} \quad \text { (E13) } \\
B^{\phi}=\beta^{(0)}+\beta^{(1)} \exp \left(-\alpha_{1} I^{1 / 2}\right)
\end{gathered}
$$

Here, $\beta^{(0)}, \beta^{(1)}$ and $C^{\phi}$ correspond to the Pitzer parameters, $v_{+}$and $v$-are the stoichiometric numbers of cations and anions, constituting $v=v_{+}+v_{-}$, and $m$ is molality of electrolyte solution $\left(\mathrm{mol} \mathrm{kg}^{-1}\right)$. The values of $\beta^{(0)}, \beta^{(1)}$ and $C^{\phi}$ for $1-1$ type electrolytes and $(4 / 3) \beta^{(0)},(4 / 3) \beta^{(1)}$ and $\left(2^{5 / 2} / 3\right) C^{\phi}$ for $2-1$ and $1-2$ electrolytes, and the corresponding values for other types of electrolytes are listed in the Pitzer's report $^{[19,29]}$. The parameter $b$ is a constant with a value of 1.2. For the electrolytes of $1-1,2-1,1-2,3-$ $1,4-1$, and 5-1, $\alpha_{1}=2.0$ is applied. For 2-2 electrolyte, the equation (E14) with another parameters, $\beta^{(2)}$ and $\alpha_{2}$ (with the additional term of $\beta^{(2)} \exp \left(-\alpha_{2} I^{1 / 2}\right)$ in the right side of the equation (E14)) is used at $\alpha_{1}=1.4$ and $\alpha_{2}=12$. $A_{\phi}$ is the D-H constant for the osmotic function, which is expressed by the equation (E15).

$$
A_{\phi}=\frac{1}{3}\left(\frac{e}{\sqrt{D \mathrm{kT}}}\right)^{3} \sqrt{\frac{2 \pi \mathrm{d}_{0} \mathrm{~N}_{\mathrm{A}}}{1000}}
$$

The value of $A_{\phi}(0.392$ at $298.15 \mathrm{~K})$ is affected by temperature due to the significant temperature dependence of dielectric constant, $D$. To reflect the effect of temperature on the osmotic coefficient, the dielectric constant dependent on temperature, i.e., the equation (E16), is used in calculating the value of $A_{\phi}^{[18]}$. 


$$
D=\sum_{i=0}^{4} \sum_{j=0}^{4-i} e_{i j} t^{i} d_{w}^{j}
$$

In the equation (E16), $e_{i j}$ is an array of temperature and pressure independent coefficients determined by least-squares fit of the data on the static dielectric constant of water, $t$ is the temperature $\left({ }^{\circ} \mathrm{C}\right)$, and $d_{w}$ is the density of pure water. The resulting value for $10{ }^{\circ} \mathrm{C}$ is $A_{\phi}=0.3820$. For $\mathrm{NaCl}$, the temperature dependence of $\beta^{(0)}, \beta^{(1)}$ and $C^{\phi}$ is represented by the general forms of $(\mathbf{E 1 7})-(\mathbf{E 1 9})^{[18]}$ :

$$
\begin{gathered}
\beta^{(0)}=q_{1}+q_{2}\left(\frac{1}{\mathrm{~T}}-\frac{1}{\mathrm{~T}_{\mathrm{r}}}\right)+q_{3} \ln \left(\mathrm{T} / \mathrm{T}_{\mathrm{r}}\right)+q_{4}\left(\mathrm{~T}-\mathrm{T}_{\mathrm{r}}\right)+q_{5}\left(\mathrm{~T}^{2}-\mathrm{T}_{\mathrm{r}}^{2}\right) \\
\beta^{(1)}=q_{6}+q_{9}\left(\mathrm{~T}-\mathrm{T}_{\mathrm{r}}\right)+q_{10}\left(\mathrm{~T}^{2}-\mathrm{T}_{\mathrm{r}}^{2}\right) \\
C^{\phi}=q_{11}+q_{12}\left(\frac{1}{\mathrm{~T}}-\frac{1}{\mathrm{~T}_{\mathrm{r}}}\right)+q_{13} \ln \left(\mathrm{T} / \mathrm{T}_{\mathrm{r}}\right)+q_{14}\left(\mathrm{~T}-\mathrm{T}_{\mathrm{r}}\right)
\end{gathered}
$$

where $\mathrm{T}_{\mathrm{r}}$ is $298.15 \mathrm{~K}$, and the $q$ values determined by least-squares fit of the osmotic activity coefficient data are listed in the original report ${ }^{[18]}$. The osmotic coefficients at $10{ }^{\circ} \mathrm{C}$ for $\mathrm{NaCl}$ solutions were calculated by using $b=1.2, \alpha_{1}=2.0, A_{\phi}=0.3820$ and the Pitzer parameters at $10{ }^{\circ} \mathrm{C}$ derived by the equations of (E17)-(E19).

For the salts other than $\mathrm{NaCl}$, the effect of temperature on the Pitzer parameters, within the moderate range of temperature change, can be corrected by using the temperature derivatives of $\beta^{(0)}$, $\beta^{(1)}, \beta^{(2)}$ and $C^{\phi[30]}$. The values of $\left(\partial \beta^{(0)} / \partial \mathrm{T}\right)_{\mathrm{P}},\left(\partial \beta^{(1)} / \partial \mathrm{T}\right)_{\mathrm{P}}$ and $\left(\partial C^{\varphi} / \partial \mathrm{T}\right)_{\mathrm{P}}$ for $1-1$ type electrolytes, $(4 / 3)\left(\partial \beta^{(0)} / \partial \mathrm{T}\right)_{\mathrm{P}},(4 / 3)\left(\partial \beta^{(1)} / \partial \mathrm{T}\right)_{\mathrm{P}}$ and $\left(2^{5 / 2} / 3\right)\left(\partial C^{\varphi} / \partial \mathrm{T}\right)_{\mathrm{P}}$ for $2-1$ and $1-2$ type electrolytes, and the corresponding values for other types of electrolytes are listed in the literature, along with the applicable maximum molality ${ }^{[20,29]}$. The values of temperature derivatives were not found for some of the salts considered in this study, and otherwise, the applicable molal concentrations were quite low (at most 0.1-0.2 mol kg-1). Therefore, the calculation of the Pitzer parameters for $10{ }^{\circ} \mathrm{C}$ was made for the applicable salts, i.e., $\mathrm{LiCl}, \mathrm{NaCl}, \mathrm{KCl}, \mathrm{CsCl}$, and $\mathrm{BaCl}_{2}$. It was confirmed that the calculated osmotic coefficients were in good agreement with those obtained by the Bromley method. The deviations of the calculated values between the two methods were within $2.4 \%$. 


\section{$\underline{\text { 5. Calculation of the volume change of photonic crystal unit cell }}$}

The volume of fcc unit cell with the lattice constant of $a$ is represented by $V=a^{3}$. The lattice constant was derived from the $d_{111}$ spacing calculated by applying the Bragg's law and the Snell's law to the wavelength of the reflected light observed for the photonic crystal hydrogel membrane. In the osmotic experiment, the photonic crystal hydrogel immersed in water was enclosed in the quartz cell with the flow channels of the salt solution. In this case, the incident light illuminated from the optical fiber passes through the different refractive media, i.e., the air, quartz plate and water (or salt solutions), to reach the hydrogel membrane. Therefore, the refraction of light at the three different interfaces is taken into consideration for the Bragg diffraction. The Snell's law for the refraction at three different interfaces is written as follows:

$$
\begin{gathered}
n_{0} \sin \theta_{0}=n_{\mathrm{p}} \sin \theta_{\mathrm{p}}=n_{\mathrm{q}} \sin \theta_{\mathrm{q}}=n_{\mathrm{r}} \sin \theta_{\mathrm{r}} \\
n_{0} \lambda_{0}=n_{\mathrm{p}} \lambda_{\mathrm{p}}=n_{\mathrm{q}} \lambda_{\mathrm{q}}=n_{\mathrm{r}} \lambda_{\mathrm{r}}
\end{gathered}
$$

where $\lambda_{0}$ and $\theta_{0}$ represent the wavelength and incident angle of illuminated light, and $\lambda_{\mathrm{p}}$ and $\theta_{\mathrm{p}}, \lambda_{\mathrm{q}}$ and $\theta_{\mathrm{q}}$, and $\lambda_{\mathrm{r}}$ and $\theta_{\mathrm{r}}$ are the wavelength and angle of the refracted light in the different refraction media, respectively. The $n_{0}, n_{\mathrm{p}}, n_{\mathrm{q}}$, and $n_{\mathrm{r}}$ correspond to the refractive indices of the different refraction media. The Bragg diffraction in the $n_{\mathrm{r}}$ medium is written as follows:

$$
m \lambda_{\mathrm{r}}=2 d_{h k l} \sin \left(90^{\circ}-\theta_{\mathrm{r}}\right)=2 d_{h k l} \cos \theta_{\mathrm{r}}
$$

where $d_{h k l}$ is the interplanar spacing between $h k l$ lattice planes, and $m$ is the order of the Bragg diffraction. From (E20), (E21) and (E22), the Bragg's law modified with the Snell's law is represented by the following equation:

$$
\lambda_{0}=\frac{2 d_{h k l}}{m} \sqrt{n_{\mathrm{r}}^{2}-n_{0}^{2} \sin ^{2} \theta_{0}}
$$

Here the refractive indices need to satisfy $n_{0}<n_{\mathrm{p}}<n_{\mathrm{q}}<n_{\mathrm{r}}$, or, otherwise, the refractive angle needs to be less than the critical angle of $\theta_{\text {crit }}$ causing the total internal reflection at the boundary between 
the two media. In the osmotic experiment, the $n_{0}$ and $n_{\mathrm{r}}$ media correspond to the air $\left(n_{0}=1\right)$ and the photonic crystal hydrogel with the fcc(111) diffraction lattice plane, respectively. Therefore, at the diffraction order of $m=1$, the equation $(\mathbf{E 2 3})$ is rewritten as follows:

$$
\lambda_{0}=2 d_{111} \sqrt{n_{\text {avg }}^{2}-\sin ^{2} \theta_{0}}
$$

The $n_{\text {avg }}$ represent the average refractive index of photonic crystal hydrogel. In the osmotic experiment, the illumination of visible light and the detection of the reflected light were conducted at the same angle of $\theta=0^{\circ}$ to the normal of the planner surface of hydrogel membrane. Thus, the lattice constant of fcc photonic crystal is calculated by the following equation:

$$
a=\sqrt{3} d_{111}=\frac{\sqrt{3}}{2} \frac{\lambda_{0}}{n_{\text {avg }}}
$$

The $n_{\text {avg }}$ is represented by the equation (E26) using the refractive index and volume fraction of each component of the photonic crystal hydrogel:

$$
n_{\text {avg }}=n_{\mathrm{SiO}_{2}} f_{\mathrm{SiO}_{2}}+n_{\text {polym }} f_{\text {polym }}+n_{\mathrm{H}_{2} \mathrm{O}} f_{\mathrm{H}_{2} \mathrm{O}}
$$

The volume fractions of silica $\left(\mathrm{SiO}_{2}\right)$, polymer $\left(f_{\text {polym }}\right)$ and water $\left(\mathrm{fH}_{2} \mathrm{O}\right)$ are derived from the volumes of components $\left(\mathrm{VSiO}_{2}, \mathrm{Vpolym}\right.$ and $\left.\mathrm{VH}_{2} \mathrm{O}\right)$ in the photonic crystal hydrogels, as is respectively represented by the following equations:

$$
\begin{aligned}
& f_{\mathrm{SiO}_{2}}=\frac{V_{\mathrm{SiO}_{2}}}{V_{\mathrm{SiO}_{2}}+V_{\text {polym }}+V_{\mathrm{H}_{2} \mathrm{O}}} \quad(\mathbf{E} 27-\mathbf{1}) \\
& f_{\text {polym }}=\frac{V_{\text {polym }}}{V_{\mathrm{SiO}_{2}}+V_{\text {polym }}+V_{\mathrm{H}_{2} \mathrm{O}}} \quad(\mathbf{E} 27-2)
\end{aligned}
$$




$$
f_{\mathrm{H}_{2} \mathrm{O}}=\frac{V_{\mathrm{H}_{2} \mathrm{O}}}{V_{\mathrm{SiO}_{2}}+V_{\text {polym }}+V_{\mathrm{H}_{2} \mathrm{O}}} \quad(\mathbf{E} 27-\mathbf{3})
$$

The volume of each component was calculated by considering the volume change of the initial aqueous suspension of colloidal crystalline array with the dialysis for solvent exchange from water to DMF and the dissolution of monomer compounds, followed by the solvent exchange of the resulting photonic crystal hydrogel from DMF to water. It was experimentally confirmed that the solvent exchange of the aqueous silica colloidal suspension to DMF expanded the volume to 1.51 times larger than the initial one, and the dissolution of NIPAAm monomer, MBA crosslinker and 2,2diethoxyacetophenone photoinitiator for the polymer synthesis further expanded the volume of $\mathrm{SiO}_{2}$ NCP-CCA/DMF to 1.18 times larger (each volume change was calculated from the average volume in the experiments carried out three times individually). Furthermore, both sides of the square membrane of the synthesized photonic crystal polymer gel (using the template of $10 \times 10 \mathrm{~mm}^{2}$, thickness: $63 \mu \mathrm{m}$ ) were expanded to about 1.15 times after the solvent exchange from DMF to water by immersing it in water. Assuming that the hydrogel membrane was uniformly expanded (in the depth direction as well), the volume of the resulting hydrogel membrane was expanded to 1.52 times by the water absorption accompanying the elimination of DMF. Based on the volume changes described above, the volume fractions of silica, polymers, and water in the photonic crystal hydrogel were calculated from the initial concentration of silica CCA aqueous dispersion (43.4 wt.\%) and $2.20 \mathrm{~g} / \mathrm{cm}^{3}$ as silica density by using the equation from (E27-1) to (E27-3), resulting in $\mathrm{SSiO}_{2}=0.095, f_{\text {polym }}=0.103$ and $\mathrm{fH}_{2} \mathrm{O}=0.803$, respectively. In the osmotic experiments, the volume of the hydrogel membrane was gradually changed by swelling or contraction with the variation of the concentration of the salt solutions, leading to the variation of the volume fraction of hydrogel components. Therefore, it is required to correct $n_{\text {avg }}$ with the change of volume fraction of hydrogel components. The corrected average refractive index of photonic crystal hydrogel membrane, $n_{\text {avg }}$, is represented by the following equation:

$$
n_{\text {avg }}^{\prime}=n_{\text {Sio }_{2}}\left[\left(1-\alpha \cdot f_{\mathrm{H}_{2} \mathrm{O}}\right) \times\left(\frac{f_{\text {SiO }_{2}}}{f_{\text {sio }_{2}}+f_{\text {polym }}}\right)\right]+n_{\text {polym }}\left[\left(1-\alpha \cdot f_{\mathrm{H}_{2} \mathrm{O}}\right) \times\left(\frac{f_{\text {polym }}}{f_{\text {Sio }_{2}}+f_{\text {polym }}}\right)\right]+n_{\text {soln }}\left(\alpha \cdot f_{\mathrm{H}_{2} \mathrm{O}}\right)
$$

where $n_{\text {soln }}$ is the refractive index of the salt solutions used, and $\alpha$ represents the volume ratio of the contracted (or swollen) hydrogel membrane in the salt solution to the initial hydrogel membrane in water, which can be regarded equivalent to the volume ratio $\left(V^{\prime} / V_{0}\right)$ of fcc unit cells in the salt solution and in water. Thus, $\alpha$ is written as the following equation (E29) by using the equation (E25): 


$$
\alpha=\frac{V^{\prime}}{V_{0}}=\frac{a^{\prime 3}}{a_{0}{ }^{3}}=\left(\frac{n_{a v g} \lambda^{\prime}}{n_{\text {avg }}^{\prime} \lambda_{0}}\right)^{3}
$$

where $a_{0}, n_{\text {avg }}$ and $\lambda_{0}$ represent the fcc lattice constant, average refractive index and observed reflection wavelength for photonic crystal hydrogel membrane in water, while $a^{\prime}, n_{\text {avg }}{ }^{\prime}$ and $\lambda^{\prime}$ are the corresponding parameters for the hydrogel membrane in the salt solution. The initial volume $\left(V_{0}\right)$ of the fcc unit cell of the hydrogel membrane in water was calculated from the observed reflection wavelength by the equations (E25) and (E26). The contraction (or swelling) volume ( $\left.V^{\prime}\right)$ of the fcc unit cell of the hydrogel membrane in the salt solution was calculated by (E28) and (E29), where the value of $\alpha$ was determined by a successive approximation method with the convergence condition of establishing the equation (E29). In both calculations of $V_{0}$ and $V^{\prime}$, the literature values of refractive indices, $n \mathrm{SiO}_{2}=1.47$ (at the $\lambda$ range of $400-550 \mathrm{~nm}^{[3,4]}$ ), $n_{\text {polym }}=1.5$ (dry PNIPAAm, at $532 \mathrm{~nm}^{[31]}$ ), and $n_{H_{2} O}=1.33$ (at 589.32 $\mathrm{nm}^{[32]}$ ) were used without considering the wavelength dependence (in terms of the small variation of $\Delta \lambda$ $=15-30 \mathrm{~nm}$ from the initial reflection wavelength of $\lambda=c a .527 \mathrm{~nm}$ on the sensor membrane in ultrapure water). The refractive index, $n_{\text {soln }}$, of the salt solutions in each concentration was determined by using the correlation function obtained by curve fitting of the literature values of the refractive indices and salt concentrations for each electrolyte solution ${ }^{[33-36]}$. The literature values at room temperature were used without temperature correction due to the generally quite small temperature dependence of the refractive indices of the salt solutions. All the curve fitting results provided the determination coefficient $\mathrm{R}^{2}=1$.

Using the calculated $V_{0}$ and $V^{\prime}$, the volume change of the fcc unit cell, $\Delta V_{\text {fcc }}$, was determined according to the equation $(\mathbf{E 3 0})$ :

$$
\Delta V_{\mathrm{fcc}}=V_{0}-V^{\prime}
$$

Therefore, the positive or negative values of $\Delta V_{\mathrm{fcc}}$ represent the contraction or swelling of the photonic crystal PNIPAAm hydrogel membrane in the salt solution, respectively. 


\section{$\underline{6 . ~ R e f e r e n c e s}$}

[1] Wang, L., Tikhonov, A. \& Asher, S. A. Silica crystalline colloidal array deep ultraviolet narrowband diffraction devices. Appl. Spectr. 66, 426-431 (2012).

[2] Hiltner, P. A., Papir, Y. S. \& Krieger, I. M. Diffraction of light by nonaqueous ordered suspensions. J. Phys. Chem. 75, 1881-1886 (1971).

[3] Khlebtsov, B. N., Khanadeev, V. A. \& Khlebtsov, N. G. Determination of the size, concentration, and refractive index of silica nanoparticles from turbidity spectra. Langmuir 24, 8964-8970 (2008).

[4] Waxler, R. M. \& Cleek, G. W. Refractive indices of fused silica at low temperatures. J. Res. Natl. Stand, Sec. A 75A, 279-281 (1971).

[5] Franks, G. V. Zeta Potentials and yield stresses of silica suspensions in concentrated monovalent electrolytes: isoelectric point shift and additional attraction. J. Colloid Interf. Sci. 249, 44-51 (2002).

[6] Dishon, M., Zohar, O. \& Sivan, U. Effect of cation size and charge on the interaction between silica surfaces in 1:1, 2:1, and 3:1 aqueous electrolytes. Langmuir 27, 12977-12984 (2011).

[7] Hocine, S., Hartkamp, R., Siboulet, B., Duvail, M., Coasne, B., Turq, P. \& Dufrêche, J.-F. How ion condensation occurs at a charged surface: a molecular dynamics investigation of the stern layer for water-silica interfaces. J. Phys. Chem. C 120, 963-973 (2016).

[8] E. L. DeWalt-Kerian, S. Kim, M. S. Azam, H. Zeng, Q. Liu, and J. M. Gibbs. pH-Dependent inversion of Hofmeister trends in the water structure of the electrical double layer. J. Phys. Chem. Lett. 8, 2855-2861 (2017).

[9] Hiemstra, T., De Wit, J. C. M. \& Van Riemsdijk, W. H. Multisite proton adsorption modeling at the solid/solution interface of (hydr)oxides: a new approach. J. Colloid Interf. Sci. 133, 105-117 (1989).

[10] Duval, Y., Mielczarski, J. A., Pokrovsky, O. S., Mielczarski, E. \& Ehrhardt, J. J. Evidence of the existence of three types of species at the quartz-aqueous solution interface at $\mathrm{pH} 0-10$ : XPS surface group quantification and surface complexation modeling. J. Phys. Chem. B 106, 2937-2945 (2002).

[11] Ong, S., Zhao, X., \& Eisenthal, K. B. Polarization of water molecules at a charged interface: second harmonic studies of the silica/water interface. Chem. Phys. Lett. 191, 327-335 (1992). 
[12] Pfeiffer-Laplaud, M., Costa, D., Tielens, F., Gaigeot, M.-P. \& Sulpizi, M. Bimodal acidity at the amorphous silica/water interface. J. Phys. Chem. C 119, 27354-27362 (2015).

[13] Bromley, L. A. Thermodynamic properties of strong electrolytes in aqueous solutions. AIChE J. 19, 313-320 (1973).

[14] Meissner, H. P. \& Peppas, N. A. Activity coefficients-aqueous solutions of polybasic acids and their salts. AIChE J. 19, 806-809 (1973).

[15] Meissner, H. P. \& Tester, J. W. Activity coefficients of strong electrolytes in aqueous solutions. Ind. Eng. Chem. Process Des. Dev. 11, 128-133 (1972).

[16] Meissner, H. P. \& Kusik, C. L. Activity coefficients of strong electrolytes in multicomponent aqueous solutions. AIChE J. 18, 294-298 (1972).

[17] Meissner, H. P., Kusik, C. L. \& Tester, J. W. Activity coefficients of strong electrolytes in aqueous solution-effect of temperature. AIChE J. 18, 661-662 (1972).

[18] Silvester, L. F. \& Pitzer, K. S. Thermodynamics of electrolytes. 8. High-temperature properties, including enthalpy and heat capacity, with application to sodium chloride. J. Phys. Chem. 81, 1822-1828 (1977).

[19] Pitzer, K. S. \& Mayorga, G. Thermodynamics of electrolytes. II. Activity and osmotic coefficients for strong electrolytes with one or both ions univalent. J. Phys. Chem. 77, 2300-2308 (1973).

[20] Silvester, L. F. \& Pitzer, K. S. Thermodynamics of electrolytes. X. Enthalpy and the effect of temperature on the activity coefficients. J. Sol. Chem. 7, 327-337 (1978).

[21] Zemaitis, Jr., J. F., Clark, D. M., Rafal, M. \& Scrivner, N. C. Handbook of Aqueous Electrolyte Thermodynamics: Theory \& Application (American Institute of Chemical Engineers, Inc. 1986), Chap. IV, pp.84-86.

[22] Zemaitis, Jr., J. F., Clark, D. M., Rafal, M. \& Scrivner, N. C. Handbook of Aqueous Electrolyte Thermodynamics: Theory \& Application (American Institute of Chemical Engineers, Inc. 1986), Chap. IV, pp.48-55.

[23] Lide, D. R., ed. CRC Handbook of Chemistry and Physics, Internet Version 2005, Section 8, pp 58-84, CRC Press, Boca Raton, FL, 2005. The molality and molarity for the salt solutions of $\mathrm{LiCl}, \mathrm{NaCl}, \mathrm{KCl}, \mathrm{CsCl}, \mathrm{MgCl}_{2}, \mathrm{CaCl}_{2}, \mathrm{SrCl}_{2}, \mathrm{BaCl}_{2}, \mathrm{NaNO}_{3}$, and $\mathrm{KNO}_{3}$ were cited.

[24] Pearce, J. N. \& Nelson, A. F. The vapor pressures of aqueous solutions of lithium nitrate and the activity coefficients of some alkali salts in solutions of high concentration at $25^{\circ}$. J. Am. Chem. 
Soc. 54, 3544-3555 (1932). The molality and density of $\mathrm{LiNO}_{3}$ were cited from this literature, and the molality was converted to the molarity by using the density.

[25] Merton, T. R. The viscosity and density of caesium nitrate solutions. J. Chem. Soc. Trans. 97, 2454-2463 (1910). The parts of $\mathrm{CsNO}_{3}$ in $100 \mathrm{~g}$ of water and specific gravity were cited from this literature, and the molality and molarity were calculated by using these parameters.

[26] Doan, T. H. \& Sangster, J. Viscosities of concentrated aqueous solutions of some 1:1, 2:1, and 3:1 nitrates at $25 \mathrm{C}^{\circ}$. J. Chem. Eng. Data 26, 141-144 (1981). The molality and density of $\mathrm{Mg}\left(\mathrm{NO}_{3}\right)_{2}$ were cited from this literature, and the molality was converted to the molarity by using the density.

[27] Pearce, J. N. \& Blackman, L. E. The vapor pressures and activity coefficients of aqueous solutions of calcium and aluminum nitrates at $25^{\circ}$. J. Am. Chem. Soc. 57, $24-27$ (1935). The molality and density of $\mathrm{Ca}\left(\mathrm{NO}_{3}\right)_{2}$ were cited from this literature, and the molality was converted to the molarity by using the density.

[28] Martínez-Andreu, A., Vercher, E. \& Peña, M. P. Apparent molar volumes of strontium nitrate and copper(II) chloride in ethanol + water at 298.15K. J. Chem. Eng. Data 44, 86-92 (1999). The molarity and density of $\operatorname{Sr}\left(\mathrm{NO}_{3}\right)_{2}$ were cited from this literature, and the molarity was converted to the molality by using the density.

[29] Zemaitis, Jr., J. F., Clark, D. M., Rafal, M. \& Scrivner, N. C. Handbook of Aqueous Electrolyte Thermodynamics: Theory \& Application (American Institute of Chemical Engineers, Inc. 1986), Chap. IV, pp.188-190.

[30] Zemaitis, Jr., J. F., Clark, D. M., Rafal, M. \& Scrivner, N. C. Handbook of Aqueous Electrolyte Thermodynamics: Theory \& Application (American Institute of Chemical Engineers, Inc. 1986), Chap. IV, pp.86-88.

[31] Zhou, S. \& Wu, C. In-situ interferometry studies of the drying and swelling kinetics of an ultrathin poly( $N$-isopropylacrylamide) gel film below and above its volume phase transition temperature. Macromolecules 29, 4998-5001 (1996).

[32] Thormählen, I., Straub, J. \& Grigull, U. Refractive index of water and its dependence on wavelength, temperature, and density. J. Phys. Chem. Ref. Data 14, 933-945 (1985).

[33] The refractive indices and molarities of the salt solutions of $\mathrm{LiCl}, \mathrm{NaCl}, \mathrm{KCl}, \mathrm{CsCl}, \mathrm{MgCl}_{2}$, $\mathrm{CaCl}_{2}, \mathrm{SrCl}_{2}, \mathrm{BaCl}_{2}, \mathrm{NaNO}_{3}$, and $\mathrm{KNO}_{3}$ were cited from the ref. [23].

[34] Merland, A. Two experimental laws relating index of refraction to concentration of solution. Compt. rend. 227, 189-90 (1948). The refractive index of $\mathrm{Mg}\left(\mathrm{NO}_{3}\right)_{2}$ solution in each concentration 
was calculated by using the reported correlation equation of refractive index vs molarity with the specific coefficients.

[35] Miller, G. A. Piezo-optic coefficient of some aqueous electrolytes. J. Chem. Eng. Data 21, 188-189 (1976). The refractive indices and molality of $\mathrm{Ca}\left(\mathrm{NO}_{3}\right)_{2}$ solution were cited.

[36] Dash, D. Thermodynamics of ion interaction in solvent extraction, chapter 4: Structural interactions leading to volumetric changes in aqueous nitrate solutions at 298.15 K. 2013 Thesis (Homi Bhabha National Institute). The refractive indices of $\mathrm{CsNO}_{3}$ and $\operatorname{Sr}\left(\mathrm{NO}_{3}\right)_{2}$ solutions in the given salt concentrations were calculated by using the reported correlation equation of refractive index vs molality with the respectively different coefficients. 